\title{
Optimization of an Advanced Hybrid Wing Body Concept using HCDstruct Version 1.2
}

\author{
Jesse R. Quinlan* and Frank H. Gern ${ }^{\dagger}$ \\ NASA Langley Research Center, Hampton, VA, 23681
}

\begin{abstract}
Hybrid Wing Body (HWB) aircraft concepts continue to be promising candidates for achieving the simultaneous fuel consumption and noise reduction goals set forth by NASA's Environmentally Responsible Aviation (ERA) project. In order to evaluate the projected benefits, improvements in structural analysis at the conceptual design level were necessary; thus, NASA researchers developed the Hybrid wing body Conceptual Design and structural optimization (HCDstruct) tool to perform aeroservoelastic structural optimizations of advanced HWB concepts. In this paper, the authors present substantial updates to the HCDstruct tool and related analysis, including: the addition of four inboard and eight outboard control surfaces and two all-movable tail/rudder assemblies, providing a full aeroservoelastic analysis capability; the implementation of asymmetric load cases for structural sizing applications; and a methodology for minimizing control surface actuation power using NASTRAN SOL 200 and HCDstruct's aeroservoelastic finite-element model (FEM).
\end{abstract}

\section{Nomenclature}

$\begin{array}{ll}\text { AATT } & =\text { Advanced Aircraft Transport Technology } \\ \text { ANGLEA } & =\text { Angle of attack degree of freedom } \\ \text { ANN } & =\text { Artificial Neural Network } \\ \text { AOA } & =\text { Angle of attack in degrees } \\ \text { ARMD } & =\text { Aeronautics Research Mission Directorate } \\ \text { BWB } & =\text { Blended Wing Body } \\ \text { CFD } & =\text { Computational Fluid Dynamics } \\ \text { DLM } & =\text { Doublet-Lattice Method } \\ \text { EL } & =\text { Deflection of elevator in degrees } \\ \text { ERA } & =\text { Environmentally Responsible Aviation Project at NASA } \\ \text { FEM } & =\text { Finite Element Model } \\ \text { FLOPS } & =\text { Flight Optimization System } \\ \text { GA } & =\text { Genetic Algorithm } \\ \text { HCDstruct } & =\text { Hybrid wing body Conceptual Design and structural optimization } \\ \text { HWB } & =\text { Hybrid Wing Body } \\ \text { IN } & =\text { Deflection angle of inner elevon } N \text { in degrees } \\ \text { LaRC } & =\text { Langley Research Center } \\ \text { LHS } & =\text { Latin Hypercube Sampling } \\ \text { MDOPT } & =\text { Multidisciplinary Design Optimization } \\ \text { NASA } & =\text { National Aeronautics and Space Administration } \\ \text { ND8 } & =\text { NASA D8 } \\ \text { ON } & =\text { Deflection of outer elevon } N \text { in degrees } \\ \text { OpenVSP } & =\text { Open Vehicle Sketch Pad } \\ \text { OREIO } & =\text { Boeing Open Rotor Engine Integration on a BWB } \\ \text { PDF } & =\text { Probability Density Function }\end{array}$

*Aerospace Engineer, Aeronautics Systems Analysis Branch, 1 N Dryden Street, and AIAA Member.

${ }^{\dagger}$ Assistant Branch Head, Vehicle Analysis Branch, 1 N Dryden Street, and AIAA Member. 


$\begin{array}{ll}\mathrm{PSI} & =\text { Pounds-per-square-inch } \\ \mathrm{R} N & =\text { Deflection of rudder } N \text { in degrees } \\ \mathrm{TE} & =\text { Trailing Edge } \\ \mathrm{UI} & =\text { User Interface } \\ \mathrm{URDD} N & =\text { Degree of freedom } N\end{array}$

\section{Introduction}

$\mathrm{H}^{2}$ YBRID wing body (HWB) or Blended Wing Body (BWB) aircraft concepts are considered promising alternatives to conventional tube and wing configurations due to their large potential fuel savings and increased aerodynamic efficiency. ${ }^{1}$ Fuel burn reductions of $25 \%$ and higher have been published for some ultra-high capacity configurations carrying up to 800 passengers. Most notable is the work of Liebeck and his co-workers at The Boeing Company. Their 450 passenger BWB-4501L design resulted in the $8.5 \%$ scale $\mathrm{X}-48 \mathrm{~B}$ flight demonstrator shown in Fig. $1{ }^{2}$

A significant difficulty in dealing with HWB design optimization has always been the lack of a data base of known flying designs which may serve as calibration and validation points for conceptual design and optimization programs like Flight Optimization System (FLOPS), ${ }^{3}$ especially when compared to the vast amount of available tube and wing aircraft data. When transitioning from the conceptual to the preliminary design phase, the aircraft designer needs to be sure that the design chosen for further optimization is actually a viable design, and as a result of the lack of validation cases, the development of improved fidelity analysis tools becomes imperative for the conceptual design loop.

To validate the projected fuel burn and noise reduction potential of HWB designs for NASA's Environmentally Respon-

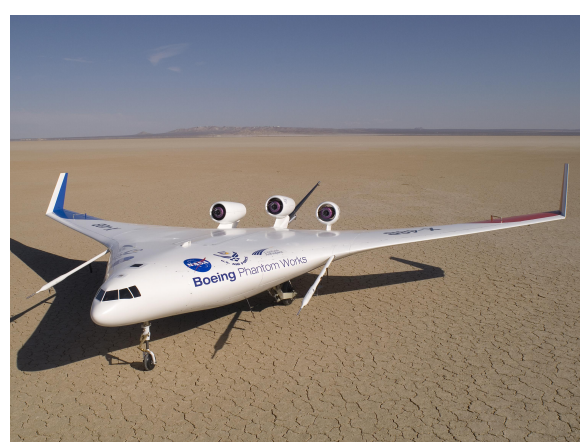

Figure 1. Boeing's X-48B Blended Wing Body flight demonstrator (NASA Photo).

sible Aviation (ERA) project, significant efforts have been put forward to develop advanced structural and aerodynamic analysis tools for HWB conceptual design optimization. Aerodynamic methods improvement has been geared towards increased fidelity in-the-loop methods like enhanced panel codes and computational fluid dynamics (CFD). ${ }^{4}$ Recently developed structures tools include finite element model (FEM) based analyses to provide enhanced capabilities for HWB centerbody sizing and weight estimation which recently led to the approval for public release of the HCDstruct tool (Hybrid wing body Conceptual Design and structural analysis $).{ }^{5,6}$

The current paper first describes updates to HCDstruct reflected in the latest release, hereafter referred to as HCDstruct Version 1.2 (V1.2). Specifically, the additional aeroservoelastic analysis capabilities are described as related to the recent inclusion of four inboard and eight outboard elevons and two all-movable tail or rudder assemblies. Next, several asymmetric load and maneuver cases recently added to the structural optimization analysis are described, and related results are presented using the Boeing Open Rotor Engine Integration on a BWB (OREIO) concept. Finally, work toward optimizing maneuver control surface deflection schedules for HWB vehicles with multiple redundant control surfaces is presented.

\section{HCDstruct Version 1.2 Development}

Following years of development and several applications ${ }^{4-10}$ of earlier tool versions utilizing a symmetric half-model formulation, HCDstruct V1.2 has recently been approved for release by NASA Langley Research Center (LaRC) as a substantial update to the original software. This latest version is based on a full wing-tip-to-wing-tip model formulation that also includes numerous control surface configuration options. Additionally, the original set of load cases used to constrain the structural optimization has been expanded to now include asymmetric maneuvers. The release of HCDstruct V1.2 also includes complete input and output decks for the Boeing OREIO HWB concept, and in contrast to the original version, the latest software version is deployed as a stand-alone, Windows executable requiring no additional licensed software.

Detailed overviews of HCDstruct V1.0 and V1.1 are available in the literature; ${ }^{4,6,7}$ thus, in this section, 
only new details of HCDstruct V1.2 are discussed. In the first section, II.A, newly-available control surface configuration options available in HCDstruct V1.2 are presented. Next, in section II.B, the asymmetric maneuver load cases recently added to the HCDstruct V1.2 optimization analysis are described. Finally, in section II.C, structural optimization results for the Boeing OREIO are compared to those of the previous release, with particular emphasis on the increased fidelity of the aft body sizing due to the inclusion of asymmetric loadings.

\section{II.A. Aeroservoelastic Capability}

In addition to implementing and verifying the full wing-tip-to-wing-tip model formulation and the refined user-interface (UI), the primary development for HCDstruct V1.2 consisted of configuring and verifying inboard and outboard wing and tail control surfaces. The Boeing OREIO configuration, for which an Open Vehicle Sketch Pad (OpenVSP) ${ }^{11}$ model and full-model HCDstruct FEM are shown in Fig. 2, was used as the baseline configuration in support of this developmental work. In Fig. 2, the HCDstruct FEM also includes the control surface coordinate systems, systems weights as concentrated masses, and rigid bars used to support the propulsion systems and vertical tails. In addition to the central elevons (elevators), the as-designed Boeing OREIO also included eight outboard wing elevons, four inboard wing elevons, two all-movable vertical tails, two rudder surfaces on the vertical tails, and high-lift Kreuger flaps at the leading edges of the wings.
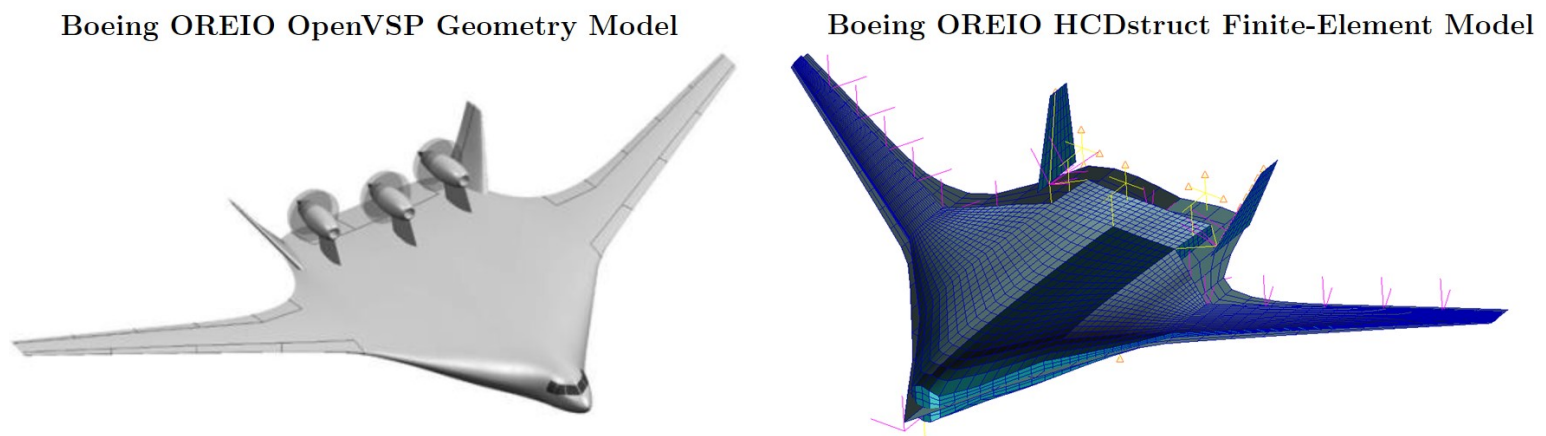

Figure 2. OpenVSP model of the Boeing OREIO concept (left) and HCDstruct V1.2 finite-element model of the same Boeing OREIO configuration (right).

In HCDstruct V1.0, the only control surface modeled was the single starboard-side elevator, as this was the only surface required to trim the symmetric half-model in pitch. In the current version of the software, the inboard and outboard wing elevons and the all-movable tails and rudders were implemented and configured for use with both the symmetric half-model FEM and also the full wing-tip-to-wing-tip FEM formulation. The leading edge flaps included in the as-designed OREIO configuration were not modeled for this effort since they are of little utility in the selected critical load cases used to constrain the structural optimization. Thus, the half-model now supports up to eight independent control surfaces and the full model up to 16 independent control surfaces, noting that the user may only select either of the all-movable tail or rudder. The control surfaces available in HCDstruct V1.2 are highlighted on the FEM model of the OREIO in Fig. 3, where the outboard elevons are shown in green, the inboard elevons are shown in yellow, the central elevons are shown in red, the rudders are shown in blue, and the all-movable tails shown in orange. In its current implementation, these control surfaces are aerodynamically modeled, only. That is, the control surfaces are comprised of Doublet-Lattice Method (DLM) panel elements for which the aerodynamic forces are splined to the wing rear spar.

The control surfaces can be configured either by direct linking (via NASTRAN ${ }^{12}$ AELINK specifications), where the surface deflections are linked to those of the two central elevons, or by specifying individual deflections directly (via NASTRAN TRIM specifications). For both cases, the user can provide AELINK coefficients or surface deflections, respectively, in the HCDstruct executive input deck. These additional control surface configuration options now permit the application of asymmetric maneuvers for the full wingtip-to-wing-tip model, which are discussed in the following section. 


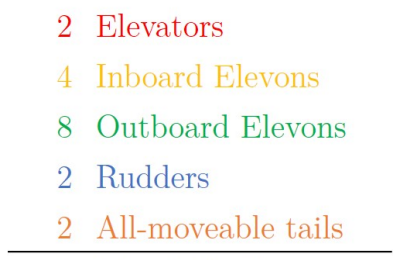

18 Total Surfaces

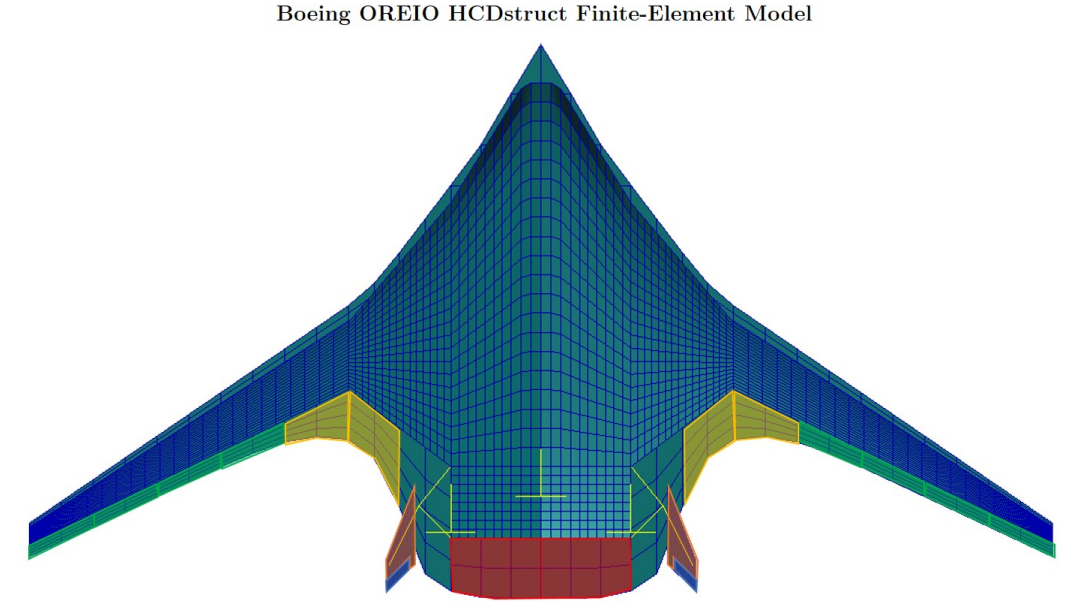

Figure 3. Control surfaces configured and available for use in HCDstruct V1.2 shown overlaid on the top-view of the Boeing OREIO HCDstruct V1.2 finite-element model.

\section{II.B. Asymmetric Load Cases}

As was suggested in previous studies, ${ }^{6,10}$ significant uncertainty associated with predictions of the structural weight for advanced HWB concepts is likely attributed to the aft body assembly. For HWB concepts like the OREIO, the aft body must be designed to carry the inertial loads of the propulsion systems, vertical tails, and skins and also the bending loads associated with the central elevon hinge moments and any loads on the aft body due to asymmetric maneuvers or engine-out conditions. While the original version of HCDstruct did size the aft body structure for the inertial loads of the vertical tails and propulsion systems, only symmetric load cases were available for the analysis.

Another major development to HCDstruct for V1.2 was the implementation of asymmetric load cases, in addition to the four symmetric load cases available in V1.0. These additional asymmetric load cases include a 1.0-G dynamic overswing maneuver and a 1.0-G rudder reversal maneuver. For these asymmetric maneuvers, the full wing-tip-to-wing-tip model is constrained rigidly at the nose grid point in the streamwise direction only; all other translational and rotational degrees of freedom are constrained using reactionary forces and moments via SUPORT1 NASTRAN specifications. A summary of these additional asymmetric cases are shown in Table 1, in addition to those of the original symmetric load cases, where ANGLEA refers to the angle of attack; URDD2 refers to the lateral acceleration; URDD5 refers to the pitch acceleration; and URDD6 refers to the yaw acceleration. The non-free aeroelastic degrees of freedom (AESTAT) specified on the TRIM cards for the asymmetric load cases include: SIDES (sideslip angle), ROLL (roll rate), PITCH (pitch rate), YAW (yaw rate), URDD3 (vertical acceleration), and URDD4 (roll acceleration). The fixed aeroelastic degrees of freedom specified on the TRIM cards for the symmetric load cases include those of the asymmetric loads and URDD2, URDD5, and URDD6. Additionally, for dynamic overswing and rudder reversal load cases, the rudder control surface deflections and sideslip angles are specified according to Ref. 13.

Table 1. Summary of load cases used by HCDstruct for structural optimization of HWB aircraft concepts.

\begin{tabular}{cllll}
\hline \hline Case & Class & Description & Free Trim Variables & Availability \\
\hline 1 & Symmetric & 2.5-G Limit Load & ANGLEA & V1.0+ \\
2 & Symmetric & $-1.0-$ G Limit Load & ANGLEA & V1.0+ \\
3 & Symmetric & 2.0-G Taxi Bump & ANGLEA & V1.0+ \\
4 & Symmetric & 2P Cabin Overpressurization & ANGLEA & V1.0+ \\
\hline \hline 5 & Asymmetric & 1.0-G Dynamic Overswing & ANGLEA, URDD: $2,5,6$ & V1.2+ \\
6 & Asymmetric & 1.0-G Rudder Reversal & ANGLEA, URDD: 2, 5, 6 & V1.2+ \\
\hline
\end{tabular}




\section{II.C. Boeing OREIO Results}

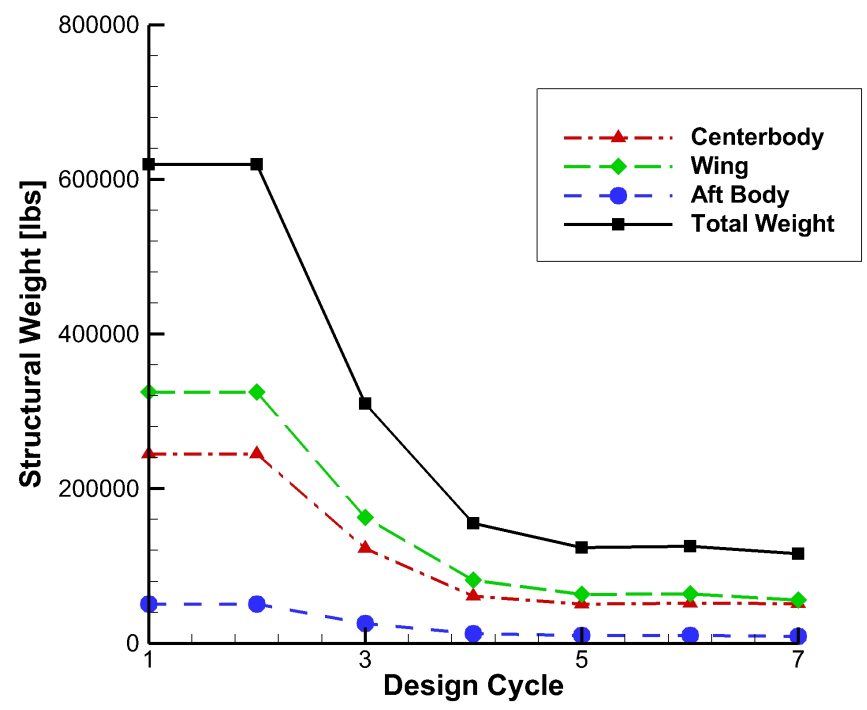

Figure 4. Component and total structural weight convergence history for Boeing OREIO optimization using HCDstruct V1.2.

The Boeing OREIO concept was structurally optimized using HCDstruct V1.2 with the control surface configuration and load cases described in the previous section, and the results of this optimization are compared to those of previous studies. ${ }^{7,10}$ The weight convergence history is shown in Fig. 4 for the present analysis, demonstrating relative convergence of the total structural weight. In Fig. 5, the component-level and total structural weight predictions for the OREIO using HCDstruct V1.2 are compared to those of previous studies using HCDstruct V1.0, FLOPS, ${ }^{3}$ and Boeing's multidisciplinary optimization (MDOPT) approach. ${ }^{14}$ As compared to the results of HCDstruct V1.0, the aggregate effect of all the HCDstruct V1.2 developments was to drive the structural weight predictions lower and nearer to the Boeing MDOPT results, which represent the highest-fidelity optimization analysis referenced in this work. Specifically, the aft body structural weight prediction agrees significantly better with that of Boeing at about $56 \%$ different as compared to about $136 \%$ different using HCDstruct V1.0. While the wing structural weight lessened by about $8 \%$ as compared to HCDstruct V1.0, the total structural weight prediction for HCDstruct V1.2 agrees well with the results of Boeing. As was also found previously, ${ }^{10}$ the results compared less favorably to those of FLOPS, which is unsurprising due to the lack of relevant design data available for HWB concepts required to tune the reduced order weight estimation models used by FLOPS.

Aeroservoelastic analysis results for the dynamic overswing and rudder reversal load cases are shown in Figs. 6 and 7, respectively. For each figure, the optimized model displacement results are shown overlaid with contours of von Mises stress distributions for top, side, and bottom views of the Boeing OREIO, demonstrating the asymmetric loadings captured by these maneuver cases. Based on these results, the rudder reversal load case appears to stress the wing mid-sections considerably more than the dynamic overswing maneuver, while both cases place significant stress on the aft body at the points of vertical tail attachment. The load asymmetry is further apparent by inspecting the relative wing displacements for both cases.

\section{Control Surface Deflection Schedule Optimization}

One of the many benefits of HWB designs utilizing numerous trailing edge (TE) control surfaces is the inherent control redundancy. With numerous inboard and outboard elevons, for example, in addition to centrally-placed elevators, the same maneuver may be achieved with numerous control surface deflection schedules. Each of these theoretical control surface deflection schedules requires a specific actuation power, which can be formulated as an optimization problem for a specified maneuver due to the duplicity of the system. With the additional control surfaces configured for use in HCDstruct V1.2, the tool now provides a 


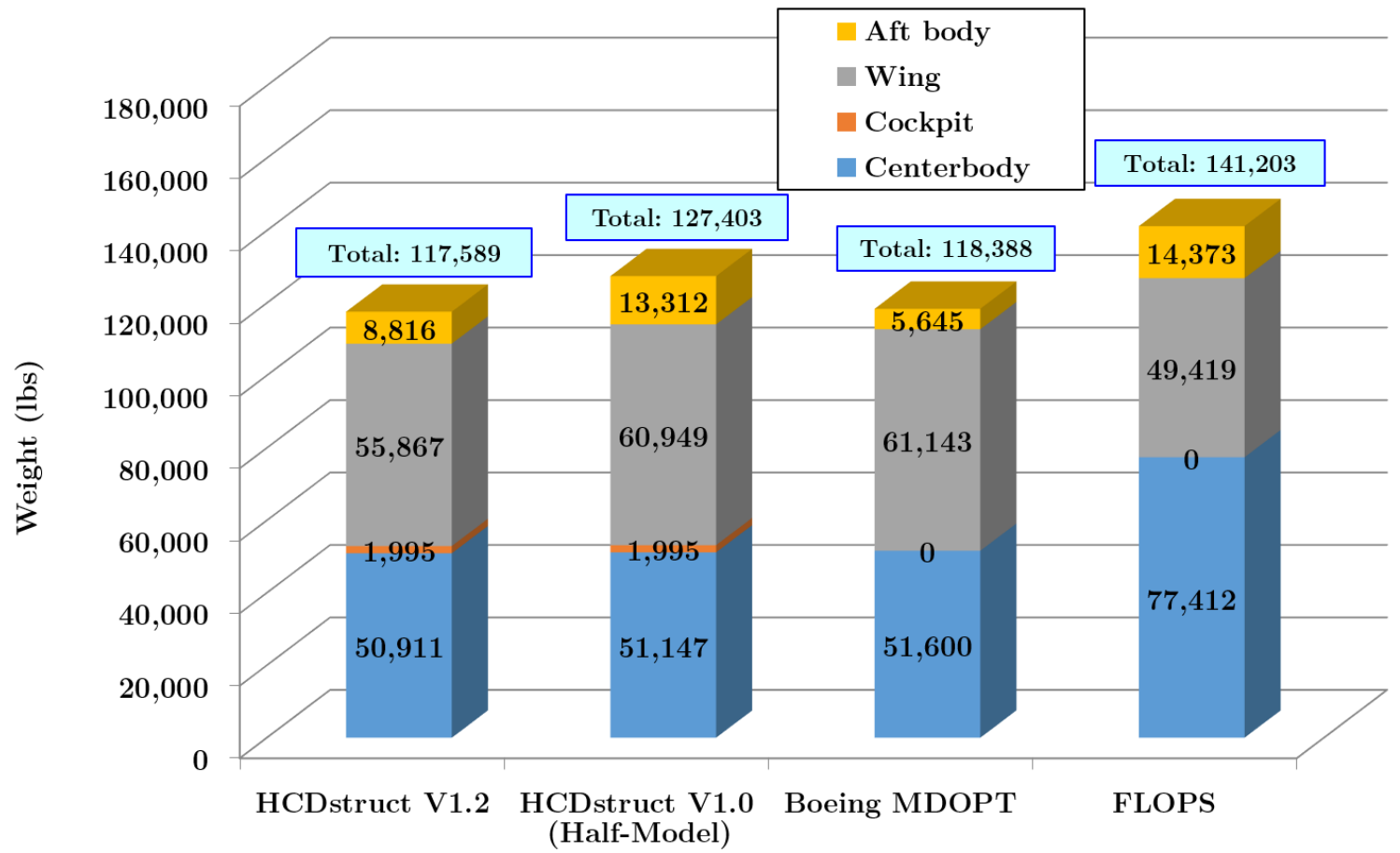

Figure 5. Comparisons of component-level and total structural weights for the Boeing OREIO concept for HCDstruct V1.2, HCDstruct V1.0, Boeing MDOPT, ${ }^{14}$ and FLOPS $^{3}$ (from left to right).

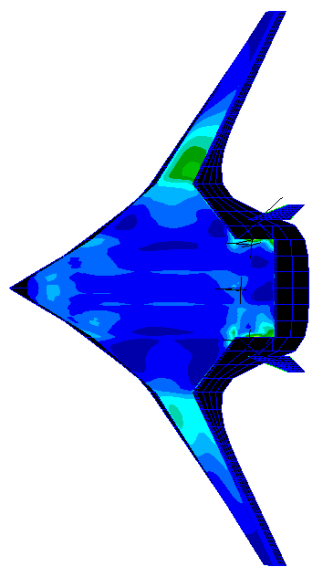

Top View

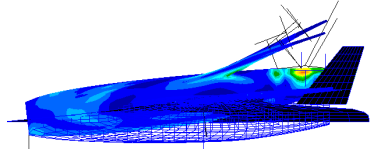

Side View

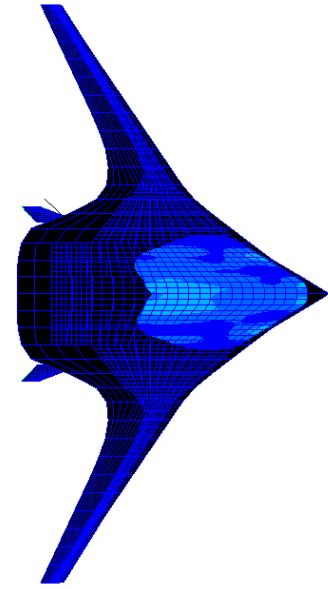

Bottom View
Von Mises Stress $[\mathbf{P S I}]$

$$
\begin{array}{r}
1.40+004 \\
1.31+004 \\
1.21+004 \\
1.12+004 \\
1.03+004 \\
9.33+003 \\
8.40+003 \\
7.47+003 \\
6.53+003 \\
5.60+003 \\
4.67+003 \\
3.73+003 \\
2.80+003 \\
1.87+003 \\
9.33+002 \\
0 .
\end{array}
$$

default_Fringe:

Max $1.28+004 @ N d 945026$ Min $4.47+000 @ N d 935075$ default_Deformation

$\operatorname{Max} 4.53+001 @ N d 31483$

Figure 6. Dynamic overswing load case results for the Boeing OREIO, where translational displacements are shown overlaid by von Mises stress contours in pounds-per-square-inch (PSI) for top, side, and bottom view, from left to right, respectively, of the optimized structural model. 


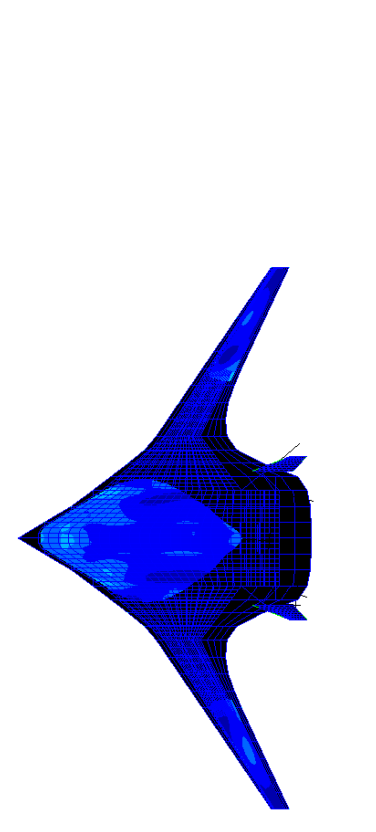

Top View

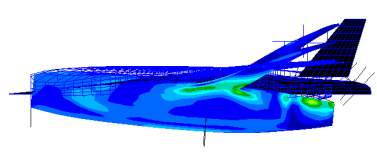

Side View

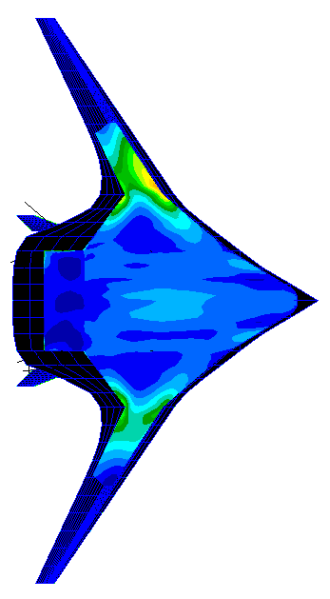

Bottom View
Von Mises Stress

[PSI]

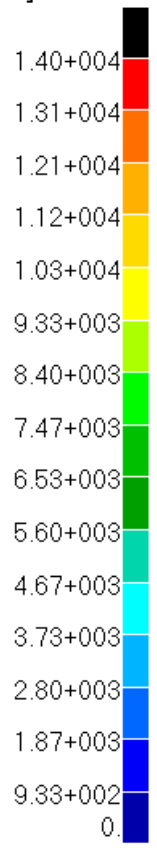

default_Fringe

Max 1.18+004@Nd 32023

$\operatorname{Min} 2.27+000 @ N d 35106$

default_Deformation :

Max3.11+001@Nd 86004

Figure 7. Rudder reversal load case results for the Boeing OREIO, where translational displacements are shown overlaid by von Mises stress contours in pounds-per-square-inch (PSI) for top, side, and bottom view, from left to right, respectively, of the optimized structural model.

platform for performing aeroservoelastic analyses in support of such an optimization effort. In the following section, III.A, a methodology for performing an optimization on the total actuation power requirements for a given maneuver is described, and in section III.B, the methodology is applied to the Boeing OREIO to optimize the actuation power required to perform a $2.5-\mathrm{G}$ pull-up maneuver.

\section{III.A. Methodology}

Significant work toward using artificial neural networks (ANNs) and genetic algorithms for minimization of actuation power for HWB concepts utilizing multiple redundant TE control surfaces has been performed by researchers at Virginia Polytechnic University (VaTech) through a NASA Aeronautics Research Mission Directorate (ARMD) Seedling Fund Project. ${ }^{8,15}$ By building a surrogate model for total required control surface hinge moment (as a proxy for actuation power) using an ANN, and combining this model with a genetic algorithm (GA) optimization, the researchers have performed computationally-efficient optimizations of total hinge-moment for a 2.5-G pull-up maneuver for the Boeing OREIO. This work has demonstrated the great potential for actuation power savings, and in fact, the latest results suggested potential actuation power savings of over $30 \%$ as compared to using the central elevators alone to perform the maneuver. In this paper, this optimization problem is approached using a more conventional gradient-based optimization method to serve as a point of comparison for the ANN and GA optimization method. To this end, the multidisciplinary gradient-based SOL 200 optimizer within NASTRAN is used to implement this methodology, and details of this approach are described below.

Due to the high-dimensionality of the optimization problem, a database of control surface deflection schedules was first constructed. Latin hypercube sampling (LHS) ${ }^{16}$ was used to populate this database of 1000 deflection schedules with all deflections bounded by $-45^{\circ}$ and $+45^{\circ}$ and modeled as normal distributions around a mean of $0^{\circ}$. The port side deflections for each schedule mirrored those of the starboard side due to the symmetry of the target maneuver. For each of these database samples, a static aeroelastic analysis 
was performed using NASTRAN SOL 144 for a symmetric 2.5-G pull-up maneuver, and the sum of the absolute hinge moments for all the control surfaces was computed according to Eq. 1, where $\phi$ is the sum of the absolute hinge moments, $H_{i}$, and serves as the objective function for subsequent optimizations. Upon completing the SOL 144 analyses, the corresponding objective function results represented a baseline measure of the total hinge moments (the proxy for actuation power) required to perform the maneuver.

$$
\phi=\sum_{i}\left|H_{i}\right|
$$

With a baseline data set for the objective function, the next step was to perform the gradient-based optimization on the total hinge moment and to identify the deflection schedule corresponding to the minimum objective function. Using the database of 1000 control surface deflection schedules as initial conditions, NASTRAN SOL 200 was configured to perform an optimization on Eq. 1. Leveraging the symmetry of the maneuver by linking the port side surfaces to those of the starboard side using AELINK cards, eight design variables required specification using DESVAR cards, including the starboard side elevator, rudder, and inboard and outboard elevons. These eight design variables were linked to aerodynamic monitor points, MONPNT1, using DVPSURF cards, for which monitor points were configured to compute the control surface hinge moment for each of the 16 control surfaces. Design responses for each of these control surfaces were defined using DRESP1 cards, which were then used in conjunction with a DEQATIN card for Eq. 1 and a composite DRESP2 response card to compute the objective function for each design cycle of SOL 200.

A Python script was written to control the entire optimization analysis, including constructing the LHS database; configuring all the SOL 144 and SOL 200 NASTRAN run files; spawning five instantiations of NASTRAN simultaneously; and post-processing the NASTRAN output files to compile the resultant trim variables and control surface hinge moment data. Using a local computing cluster, a complete SOL 200 analysis for the LHS database required approximately 21 wall clock hours. The results of this analysis for the Boeing OREIO are presented in the following section.

\section{III.B. Results for the Boeing OREIO}

For this study, five separate analyses were performed in order to both establish baseline measures for optimization results comparisons and to also investigate the effect of design variable constraints on the optimized solutions. These five analyses are described here and are summarized in Table 2. The baseline analysis case, BASELINE, consisted of trimming the aeroelastic model for a $2.5 \mathrm{G}$ maneuver using only the elevator control surfaces, with the only free variable being the elevator deflection angle. The total hinge moment required for this BASELINE case provides a measure of the conventional control approach used for fixed wing aircraft. The second analysis case, MINLHS144, refers specifically to the solution corresponding to the minimum total hinge moment solution in the database of SOL 144 static aeroelastic $2.5 \mathrm{G}$ maneuver solutions. Case MINLHS144 does not represent an optimization; rather, it is simply the minimum total hinge moment solution from the set of 1000 LHS randomized samples. The remaining analysis cases, 300LHS200, 375LHS200, and 450LHS200, correspond to the minimum total hinge moment solutions in databases of SOL 200 optimized aeroelastic $2.5 \mathrm{G}$ maneuver solutions subject to control surface deflection constraints of $30.0^{\circ}, 37.5^{\circ}$, and $45.0^{\circ}$, respectively. For SOL 200 cases, the case identifier consists of the deflection constraint, the initial condition approach, and the solution sequence. For example, case $300 L H S 200$ refers to the optimum configuration from the solution set defined by a $30.0^{\circ}$ deflection constraint (300), performed using the LHS database as initial conditions ( $L H S)$ and using solution sequence 200 (200).

Also included in Table 2 are the hinge moment figures and the net reduction in required hinge moment as compared to the BASELINE case. Based on these figures, a significant opportunity for reducing the total hinge moment required to perform a $2.5 \mathrm{G}$ maneuver exists as compared to the conventional elevatoronly approach. As the available design space was expanded by increasing the control surface deflection constraints, SOL 200 found increasingly optimal solutions. With a $30.0^{\circ}$ constraint, reductions of $11.6 \%$ in required total hinge moment were found, and as this constraint was increased to $45.0^{\circ}$, this reduction increased to approximately $42.9 \%$. Based on these results alone, there exists considerable opportunity for reducing actuation power by leveraging redundant control surfaces in conjunction with the aeroelastic flexibility of the aircraft.

With the large LHS database of control surface deflection schedules used for case MINLHS144 and the corresponding optimizations performed for 300LHS200, 375LHS200, and 450LHS200, these grouped analyses provide a substantial database of total hinge moment results that help to provide some insight into the 
Table 2. Summary of hinge-moment optimizations using SOL 200 and for baseline cases.

\begin{tabular}{cccccc}
\hline \hline Case ID & $\begin{array}{c}\text { Solution } \\
\text { Sequence }\end{array}$ & $\begin{array}{c}\text { Independent Design } \\
\text { Variables }\end{array}$ & $\begin{array}{c}\text { Deflection } \\
\text { Constraint }\end{array}$ & $\begin{array}{c}\text { Hinge } \\
\text { Moment [in-lbs] }\end{array}$ & $\begin{array}{c}\text { Reduction from } \\
\text { Baseline [\%] }\end{array}$ \\
\hline BASELINE & SOL 144 & N/A & None & $3.497 \mathrm{E}+6$ & 0.0 \\
MINLHS144 & SOL 144 & N/A & $90.0^{\circ}$ & $3.094 \mathrm{E}+6$ & 11.5 \\
300LHS200 & SOL 200 & 8 & $30.0^{\circ}$ & $3.093 \mathrm{E}+6$ & 11.6 \\
375LHS200 & SOL 200 & 8 & $37.5^{\circ}$ & $2.666 \mathrm{E}+6$ & 23.8 \\
450LHS200 & SOL 200 & 8 & $45.0^{\circ}$ & $1.996 \mathrm{E}+6$ & 42.9 \\
\hline
\end{tabular}

solution state space. This data is presented in the form of probability density functions (PDFs) in Fig. 8 to better highlight the aggregate trends present in these results. Inspecting these curves, one can immediately see the multi-dimensionality and complexity of the design space that when paired with the gradient-based optimization algorithm used in SOL 200 results in multi-modal distributions for each set of SOL 200 analyses. Further, the net effect of relaxing the design variable constraints can be seen by inspecting the 300LHS200, 375LHS200, and 450LHS200 analyses in the red (dashed line), green (dash-dot line), and purple (long-dash line) curves, respectively. As the design constraint is relaxed from $30.0^{\circ}$ to $45.0^{\circ}$, the PDF peaks shift toward lower values of the objective function, and the PDFs exhibit higher levels of variance. Furthermore, when comparing these three PDF curves to that of the SOL 144 LHS database solutions in black (solid line), one can see that the SOL 200 optimization algorithm finds significantly more-optimal solutions for every LHS database sample. The median and variance of the SOL 200 PDFs are significantly lower than that of the SOL 144 PDF.

Additional to the PDF curves, the minimum solutions for each analysis data set are annotated in Fig. 8 using the case identifiers shown in Table 2. These data points for cases MINLHS144, 300LHS200, 375LHS200, and 450LHS200 are shown in purple (diamond), green (gradient), red (delta), and black (circle), respectively, and demonstrate the relative reduction in total required hinge moment as compared to the BASELINE case shown in blue (square). By using a $30.0^{\circ}$ deflection constraint, the SOL 200 optimized solution falls nearly identically on the minimum solution in the set of SOL 144 solutions for the randomized LHS database, while both are still considerably lower than that of the BASELINE solution. By increasing the deflection constraint from $30.0^{\circ}$ to $37.5^{\circ}$ and further to $45.0^{\circ}$, the reduction in total hinge moment for the optimal solution is made more significant, where cases 300LHS200, 375LHS200, and 450LHS200 show reductions of over 4.04E+05, $8.31 \mathrm{E}+05$, and $1.50 \mathrm{E}+06$ in-lbs, respectively, or $11.6 \%, 23.8 \%$, and $42.9 \%$, respectively, as compared to the BASELINE case. These results demonstrate the significant reductions in required hinge moment achievable by leveraging the natural flexibility of the wing and the control surface redundancies along the TE to achieve the lift profile required for a trimmed 2.5-G maneuver.

Table 3. Summary of control surface deflections for baseline and optimized cases.

\begin{tabular}{cccccccccc}
\hline \hline Case ID & $\mathrm{AOA}\left[^{\circ}\right]$ & $\mathrm{EL}\left[^{\circ}\right]$ & $\mathrm{I} 1\left[^{\circ}\right]$ & $\mathrm{I} 2\left[^{\circ}\right]$ & $\mathrm{O} 1\left[^{\circ}\right]$ & $\mathrm{O} 2\left[^{\circ}\right]$ & $\mathrm{O} 3\left[^{\circ}\right]$ & $\mathrm{O} 4\left[^{\circ}\right]$ & $\mathrm{R} 1\left[^{\circ}\right]$ \\
\hline BASELINE & 6.690 & 13.900 & 0.000 & 0.000 & 0.000 & 0.000 & 0.000 & 0.000 & 0.000 \\
MINLHS144 & 7.350 & 3.360 & -9.210 & -20.800 & 41.500 & 89.600 & 5.960 & 0.375 & -0.729 \\
300LHS200 & 7.727 & 12.400 & -11.561 & -19.514 & 29.969 & 29.981 & 4.408 & -7.721 & -0.780 \\
375LHS200 & 7.734 & 9.170 & -10.797 & -20.263 & 36.358 & 36.167 & 19.602 & -6.371 & 9.165 \\
450LHS200 & 7.866 & 3.960 & -9.373 & -21.288 & 45.000 & 45.000 & 45.000 & 3.341 & 3.961 \\
\hline
\end{tabular}

As the optimizations leverage the flexibility of the airframe structure, the specific schedule of control surface deflections used to perform the $2.5 \mathrm{G}$ maneuver may change drastically. In this work, the only constraints on the optimization are the minimum and maximum deflection bounds; the airframe FEM used here was the weight-optimized model of the OREIO discussed earlier. Hence, some additional insight may be had by inspecting how the optimizer achieves the reductions in total required hinge moment via the deflection 


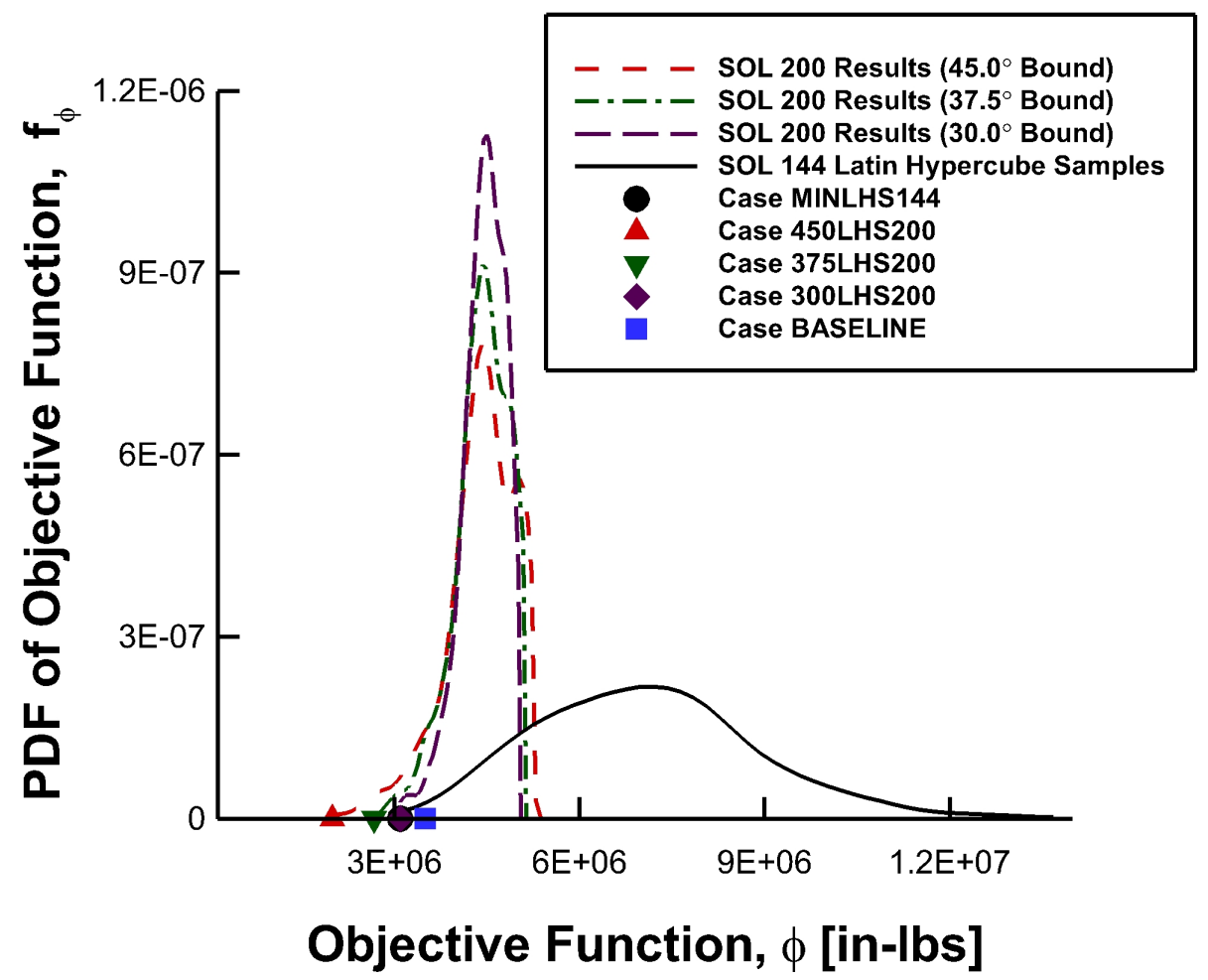

Figure 8. PDF representations of the objective function in Eq. 1 for the SOL 144 analyses (solid black line) and for the SOL 200 optimization analyses (dashed red line). The minimum solutions for the SOL 144 and SOL 200 results are represented by the black circle and red delta, respectively, and the baseline elevator-only configuration data point is shown in the blue square.

schedules. The actual deflections computed for cases BASELINE, MINLHS144, 300LHS200, 375LHS200, and 450LHS200 are summarized in Table 3 and are presented graphically in Figs. 9 and 10. In Fig. 9, the control surface deflections are shown for cases BASELINE and MINLHS144 for the elevator (EL), the inboard elevons (I1, I2), the outboard elevons (O1, O2, O3, O4), and the rudder (R1). Only the starboard control surfaces are shown, since the port side solution is necessarily identical due to the symmetry of the problem. The angle of attack (AOA) is also plotted. In Fig. 10, the same data is presented for cases 300LHS200, 375LHS200, and 450LHS200.

Comparisons of Figs. 9 and 10 and inspection of Table 3 serve to highlight the wide differences in solution control surface deflection schedules used to attain a trimmed 2.5G maneuver for these analyses. In Fig. 9, case MINLHS144 shows a stark contrast to that of case BASELINE, for which all control surface deflections besides EL are zero and the AOA is near $6.7^{\circ}$. For case MINLHS144, the AOA increases slightly while the EL decreases slightly, and the remaining control surfaces deviate strongly from zero. In fact, the outboard elevons $\mathrm{O} 1$ and $\mathrm{O} 2$ are nearly $41.5^{\circ}$ and $89.6^{\circ}$, respectively, while the remaining control surfaces exhibit deflections ranging from $-20.8^{\circ}$ to $5.96^{\circ}$. For cases 300LHS200, 375LHS200, and 450LHS200, the deflections are generally as varied; though, as the deflection constraint is increased from $30.0^{\circ}$ to $45.0^{\circ}$, for example, surfaces $\mathrm{O} 4$ and EL change direction while surface deflections for I1, I2, O1, O2, and O3 all generally increase in magnitude. Additionally, as the deflection constraint is increased, the AOA also increases slightly. From this data, it is clear that the converged control surface deflection schedule for minimal total required hinge moment is representative of the complex interplay between control surface size and configuration and the specific aerodynamic and structural modes of the model present in the aeroelastic analysis. It is within this context that one must consider the present computational results; additional considerations such as aircraft safety features, human pilot factors, and limitations of the on-board controls and actuation systems will place additional constraints on the minimum required total hinge moment or control actuation power. 


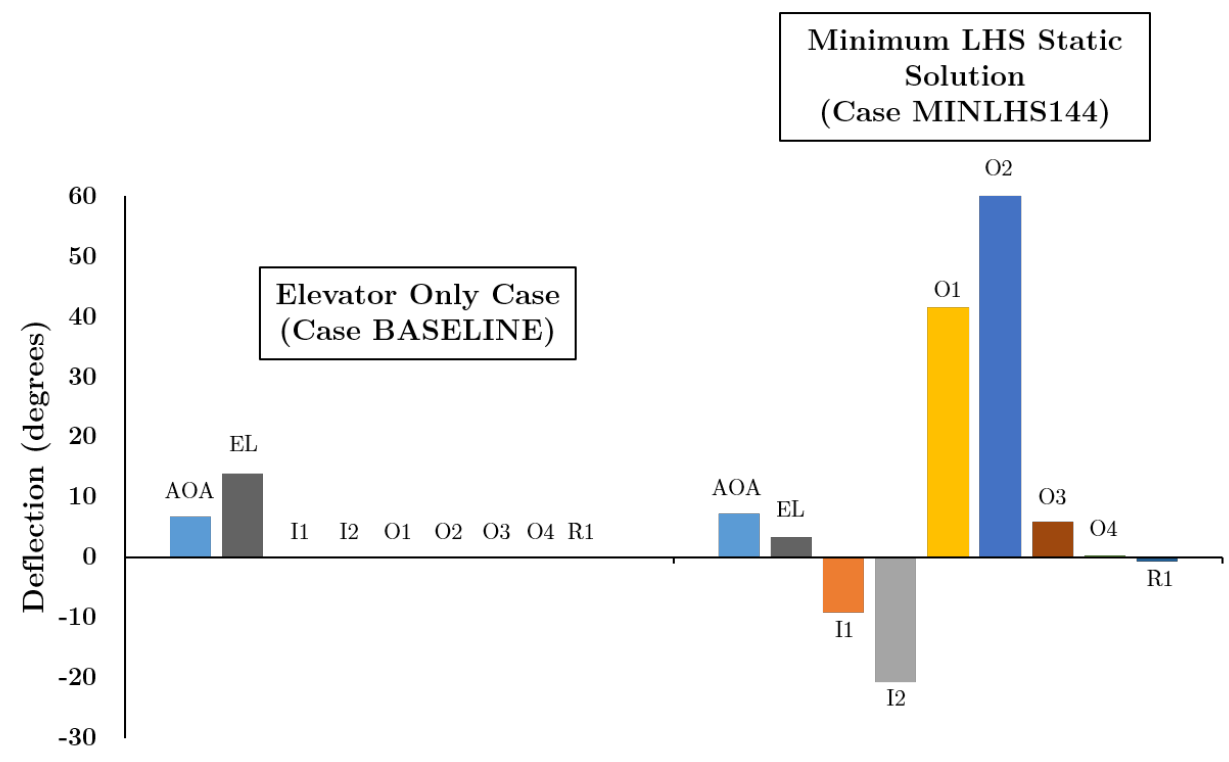

Baseline Case Control Surface Deflections

Figure 9. Column representations of the trimmed angle of attack (AOA), elevator deflection (EL), inboard elevon deflections (I1, I2), outboard elevon deflections (O1, O2, O3, O4), and rudder deflection (R1) for the elevator-only baseline case (BASELINE) and for the minimum LHS static solution case (MINLHS144), shown from left to right, respectively.

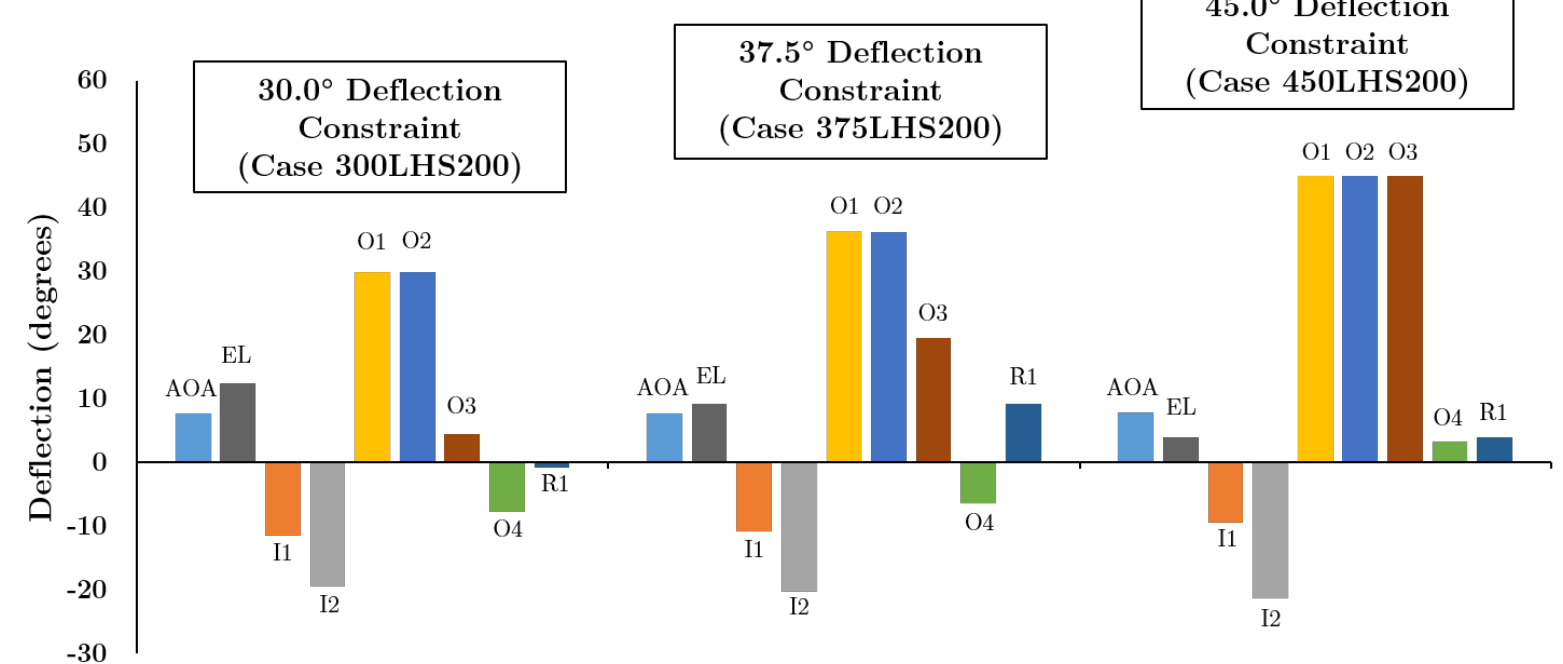

\section{Optimal Control Surface Deflections}

Figure 10. Column representations of the trimmed angle of attack (AOA), elevator deflection (EL), inboard elevon deflections (I1, I2), outboard elevon deflections (O1, O2, O3, O4), and rudder deflection (R1) for the SOL 200 optimized cases 300LHS200, 375LHS200, and 450LHS200, shown from left to right, respectively.

\section{Summary and Future Work}

The current paper first presents recent additions to the HCDstruct tool, including advanced aeroservoelastic analysis capabilities and asymmetric load cases, all of which are included in the release of HCDstruct V1.2. For verification and tractability purposes, airframe structural optimization results for the Boeing OREIO configuration were compared to those of previous HCDstruct V1.0 and to Boeing MDOPT and FLOPS analyses and were found to agree better with the results of Boeing, overall. HCDstruct now supports the configuration and use of up to 16 independent control surfaces comprising a completely actuated trailing edge, and these control surfaces are aerodynamically modeled, only. However, in future releases, these control 
surfaces will also include structural model representations.

Using in part the newly-implemented control surfaces, a gradient-based optimization methodology for minimizing actuation power requirements for an HWB concept with a high degree of control surface redundancy was developed. This methodology was developed to support a joint effort with VaTech toward the use of ANN and GA optimization of control actuation power for a HWB, where the methodology presented here served as a baseline optimization case using conventional gradient-based methods. This approach required building a LHS database of randomized control surface deflections, which were then used to perform static aeroservoelastic analyses using NASTRAN SOL 144 and subsequently used as initial conditions for optimizations on the sum of the absolute hinge moments for all of the control surfaces using NASTRAN SOL 200. Results of this analysis suggested potential reductions in total hinge moment required to perform a 2.5-G pull-up maneuver for the OREIO by nearly $43 \%$ as compared to using only the central elevators. Similar optimizations for additional maneuver cases are being pursued. Planned work also includes extending this methodology to mission performance applications to better demonstrate the viability of the optimal control surface deflection schedules identified using this approach.

The next release of HCDstruct (Version 2.0) will comprise a major update, including, among other modifications, a new user interface and the addition of a generalized tube and wing aircraft modeling capability. Furthermore, the next version will support the analysis of advanced fuselage designs like the double-bubble concept, which was implemented in support of the NASA D8 (ND8) systems analysis and design study currently underway at NASA LaRC under the Advanced Aircraft Transport Technology (AATT) project. Additionally, structural model representations of the control surfaces are being developed, and an aerodynamic matching algorithm is currently being implemented in order to match the DLM aerodynamics with available CFD data to perform flutter analysis at transonic Mach numbers.

\section{Acknowledgments}

The authors thank Craig Nickol, Rakesh Kapania, Moustaine Adegbindin, Nathan Love, and Joseph Schetz for numerous helpful discussions. This work was supported by NASA's ERA and AATT projects, with additional support from the NASA Pathways Program.

\section{References}

${ }^{1}$ Liebeck, R. H., "Design of the BWB Subsonic Transport," 40th AIAA Aerospace Sciences Meeting and Exhibit, Reno, NV, January 2002.

${ }^{2}$ Risch, T., Cosentino, G., Regan, C. D., Kisska, M., and Princen, N., "X-48B Flight-Test Progress Overview," 47th AIAA Aerospace Sciences Meeting and Exhibit, Orlando, FL, January 2009.

${ }^{3}$ McCullers, L. A., FLOPS Flight Optimization System, FLOPS Users Manual, December 2009.

${ }^{4}$ Gern, F. H., "Improved Aerodynamic Analysis for Hybrid Wing Body Concept Design Optimization," 50th AIAA Aerospace Sciences Meeting and Exhibit, Nashville, TN, January 2012.

${ }^{5}$ Gern, F. H., "Finite Element Based HWB Centerbody Structural Optimization and Weight Prediction," 53rd AIAA/ASME/ASCE/AHS/ASC Structures, Structural Dynamics, and Materials Conference, Honolulu, HI, April 2012.

${ }^{6}$ Gern, F. H., "Update on HCDstruct-A Tool for Hybrid Wing Body Conceptual Design and Structural Optimization," 15th AIAA Aviation Technology, Integration, and Operations Conference, Dallas, TX, June 2015.

${ }^{7}$ Gern, F. H., "Conceptual Design and Structural Analysis of an Open Rotor Hybrid Wing Body Aircraft," 54th AIAA/ASME/ASCE/AHS/ASC Structures, Structural Dynamics, and Materials Conference, Boston, MASS, April 2013.

${ }^{8}$ Chhabra, R., Mulani, S. B., Kapania, R. K., and Schetz, J. A., "Control Power Optimization using Artifical Intelligence for Hybrid Wing Body Aircraft," 16th AIAA/ISSMO Multidisciplinary Analysis and Optimization Conference, Dallas, TX, June 2015

${ }^{9}$ Nigam, N., Ayyalasomayajula, S., Qi, X., and Chen, P. C., "High-Fidelity Weight Estimation for Aircraft Conceptual Design Optimization," 16th AIAA/ISSMO Multidisciplinary Analysis and Optimization Conference, Dallas, TX, June 2015.

${ }^{10}$ Quinlan, J. R. and Gern, F. H., "Conceptual Design and Structural Optimization of ERA Hybrid Wing Body Concepts," AIAA SciTech Forum and Exposition, San Diego, CA, January 2016.

${ }^{11}$ Hahn, A., "Vehicle Sketch Pad: A Parametric Geometry Modeler for Conceptual Aircraft Design," 48th AIAA Aerospace Sciences Meeting and Exhibit, Orlando, FL, January 2010.

${ }^{12}$ MSC Nastran 2008, Quick Reference Guide, MSC Software Corporation, Santa Ana, CA, 2008.

${ }^{13}$ Velicki, A., "Damage Arresting Composites for Shaped Vehicles," Tech. rep., NASA/CR-2009-215932, NASA Langley Research Center, Hampton, VA, September 2009.

${ }^{14}$ LeDoux, S. T., Herling, W. W., Fatta, G. J., and Ratcliff, R. R., "MDOPT-A Multidisciplinary Design Optimization System using Higher Order Analysis Codes," 10th AIAA/ISSMO Multidisciplinary Analysis and Optimization Conference, Albany, NY, September 2004. 
${ }^{15}$ Gern, F. H., Vicroy, D., Mulani, S. B., Chhabra, R., Kapania, R. K., Schetz, J. A., Brown, D., and Princen, N. H., "Artificial Intelligence Based Control Power Optimization on Tailless Aircraft," Tech. rep., NASA/TM-2014-218671, NASA Langley Research Center, Hampton, VA, December 2014.

${ }^{16}$ McKay, M. D., Beckman, R. J., and Conover, W. J., "Comparison of Three Methods for Selecting Values of Input Variables in the Analysis of Output from a Computer Code," Technometrics, Vol. 21, No. 2, 1979, pp. 239-245. 